Observación al sentido de los procesos penales mexicanos desde el sistemismo autorreferencial Observation to the meaning of the mexican criminal trials` model by the self-steering systems theory

\title{
OBSERVACIÓN AL SENTIDO DE LOS PROCESOS PENALES MEXICANOS DESDE EL SISTEMISMO AUTORREFERENCIAL*
}

\section{OBSERVATION TO THE MEANING OF THE MEXICAN CRIMINAL TRIALS' MODEL BY THE SELF-STEERING SYSTEMS THEORY}

\author{
Elías García Rosas** - Luis Ávila Benítez***
}

\begin{abstract}
RESUMEN
El propósito del trabajo es determinar la finalidad perseguida por los procesos penales mexicanos, pues actualmente no existen referentes sustentables, teóricos ni prácticos, para ello. Se empleó la teoría de sistemas autorreferenciales luhmanniana y el método funcional, realizándose una indagación documental mediante la observación de segundo orden, al tenor de una postura constructivista sobre el conocimiento. Se alcanzó como conclusión que el sentido del proceso penal mexicano es exclusivamente la obtención de la decisión judicial definitiva, excluyéndose otros temas tradicionalmente considerados como fines procesales, entre ellos el hallazgo de la "verdad histórica", paradigma que se rompe con los resultados obtenidos.
\end{abstract}

\footnotetext{
ABSTRACT

The purpose of the research here described, was to investigate the meaning of the mexican criminal trials' model, that because there are no theorical or practical sustainable references to establish it. In the study, self-steering systems theory 
Elías García Rosas

Luis Ávila Benítez

of Niklas Luhmann and his functional method were used, developing a documental research and following a second-order observation thecnique, under a constructivistic epistemological view. Was found that the mexican trials' systemic meaning is accomplishing the definitive judicial solution, excluding other themes traditionally considered trial's goals, such as the "historic truth", paradigm which breaks down with the results achieved.

PALABRAS CLAVES

Sistemas autorreferenciales, procesos.

KEY-WORDS

Self-referencial systems, trials.

\section{Introducción}

Los autores de la materia procesal penal presentan una serie de opiniones discrepantes en torno al fin del sistema procesal penal mexicano. A la fecha no hay uniformidad en cuanto al indicado fin procesal, como tampoco un referente sustentable al respecto. Además de lo anterior, las legislaciones sobre dicha materia, así como las normas constitucionales, tampoco proporcionan indicadores firmes para el supuesto mencionado. El problema pues, es que aparece desconocido el fin jurídico de los procesos penales mexicanos y eso lleva a un sinnúmero de opiniones confusas en el campo de la sistematización procesal penal. Debido a lo anterior, la investigación pretendió una observación del comportamiento operativo de ese tipo de procesos, para develar su verdadero objetivo jurídico.

Se consideró que la teoría sistémica autorreferencial de Niklas Luhmann era adecuada para realizar la investigación, por las características que dicha visión ofrece en el abordaje de esa clase de objetos desde una postura integral normativa, dando resultados fiables y precisos a partir del uso del método funcional propio de esa tendencia.

\section{La observación de los sistemas procesales penales mexicanos desde el sistemismo autorreferencial.}

El estudio aquí reportado tomó como guía conductora al sistemismo luhmanniano por su capacidad para establecer enlaces en entramados complejos desde una óptica de apreciación y comparación crítica. No obstante, la teoría de sistemas autorreferenciales de Niklas Luhmann es omisa en sugerir algún punto de partida para iniciar observaciones hacia los diferentes tipos de redes sociales. Lo precedente deriva de que la aludida corriente de pensamiento no es lineal y por tanto deja abierta la mirada para cada investigación. Así las cosas, la apreciación hacia un entramado especial puede realizarse desde cualquier ángulo, y en la especie, se consideró que los mejores resultados serían obtenidos si la indagación se enfocara a fijar los elementos 
Observación al sentido de los procesos penales mexicanos desde el sistemismo autorreferencial Observation to the meaning of the mexican criminal trials` model by the self-steering systems theory

del sistema motivo de estudio y posteriormente se analizaran sus relaciones dentro de la red social.

Ello se efectuó así porque en el campo del sistemismo no se debe descartar la existencia de complejidad en el sistema, que se conceptúa como el grado de indeterminación en las redes sociales ricamente organizadas ${ }^{1} \mathrm{y}$ afecta originalmente a todos los entramados sociales mediante incertidumbre en los tipos de vínculos permitidos para los elementos; fue por tanto, que se buscó primero el conocimiento de los entes afectados por esa incapacidad relacional, que son los elementos sistémicos, para establecer con posterioridad sus oportunidades de interrelación. Esto obedeció también a que la autorreferencia, entendida como la capacidad operativa del sistema mediante la remisión a sus anteriores procesos, es la nota sine qua non de la postura sistémica seguida ${ }^{2}$, lo cual llevó a reforzar la necesidad de hacer el ejercicio de observación hacia los entes mencionados, que son los únicos capaces de provocar autorreferencia en la operatividad.

A efecto de realizar el hallazgo de los elementos, que son las unidades operativas sistémicas, ${ }^{3}$ se tomaron en cuenta las distinciones doctrinarias hacia los interventores del proceso penal. Previo a ello, para limitar el estudio a la fase procesal propiamente dicha, se realizó una distinción entre los "procedimientos" y los "procesos", ya que el uso de tales vocablos entraña distintos conceptos.

De esta manera, considerando la documentación bibliográfica, fue observado que los procedimientos jurídicos pueden ser de diversa índole, como los que se llevan ante autoridades notariales, registrales o ministeriales, y se les llama procedimientos, porque entrañan una serie de pasos con dirección hacia un fin particular; en cambio, hay otras actividades que también requieren de una sucesión de actos, pero donde es imprescindible la presencia de la autoridad judicial porque se intenta lograr la aplicación de la una ley determinada por parte del órgano jurisdiccional; sólo en estos casos estamos frente a lo que se conoce como proceso. ${ }^{4}$

Así, se determinó como una característica sustancial del proceso penal, la necesaria intervención judicial en el desarrollo de dichas actividades llevadas a cabo por las partes y demás involucrados en una relación jurídica, bajo un esquema regulador específico que, sin intervención del órgano judicial, sería simplemente un procedimiento.

1 Morin, Edgar, Introducción al Pensamiento Complejo, (Traducido por Pakman, Marcelo), Gedisa, Barcelona, 2007, p. 60.

Luhmann, Niklas, Sistemas Sociales, lineamientos para una teoría general, Antrophos/Universidad Iberoamericana/ CEJA/ Pontificia Universidad Javeriana, Madrid, 1998, p. 390.

Luhmann, Sistemas, cit. nota n. 2, p. 45.

Arellano García, Carlos, Teoría General del Proceso, Porrúa, México D.F., 2001, pp. 9-25; y Gómez Lara, Cipriano, Teoría General del Proceso, Harla, México, 1996, pp. 208-219. 
Elías García Rosas

Luis Ávila Benítez

En otro contexto, observando las disposiciones legales mexicanas, fue hallado que son compatibles con la opinión anterior, en el sentido de que es necesaria la actuación judicial para la existencia de un proceso. Es así, que la interpretación efectuada directamente a la Constitución Federal y a diversos códigos procedimentales, por los Ministros integrantes de las Salas de la Suprema Corte de Justicia, así como por los Magistrados miembros de los Tribunales Colegiados de Circuito, ha concluido que el proceso penal inicia desde el auto de radicación emitido por las autoridades judiciales; incluso, a ese proveído le han reconocido el nombre de "auto cabeza del proceso". 5

A partir de lo anterior, se pudo establecer que el proceso penal mexicano inicia desde que el asunto penal es consignado ante una autoridad judicial para que se avoque al conocimiento del mismo y resuelva, previas las actividades de las partes, sobre la aplicación de una ley al caso concreto de derecho penal que se ha sometido a su consideración.

Una vez sentado que para la existencia de un proceso penal se hace menester la intervención de la autoridad judicial, se distinguió con mayor facilidad en el estudio, cuáles son los elementos de un sistema procesal. Para ello se apreció a los órganos que tienen relaciones cualitativas e indelegables en su interior y se encontró al Ministerio Público; al inculpado y su defensor; y, al ente jurisdiccional, ${ }^{6}$ que sistémicamente se observan de manera respectiva como los órganos de acusación, defensa y decisión.

A esta conclusión se llegó mediante la observación del comportamiento de tales componentes al interior sistémico procesal, distinguiendo que sin alguna de dichas entidades no habría operaciones. Se partió del momento inicial del proceso, y así logró ser visto que en la consignación de la averiguación previa a los tribunales judiciales, el Ministerio Público investigador efectúa una propuesta que provoca una energización del sistema procesal, donde el órgano judicial emite un acuerdo decisorio en torno a lo solicitado, que generalmente es su aceptación competencial en el asunto.

Esta puede ser considerada como la primera acción decisoria del órgano judicial, quien desde la radicación del caso y admitida la competencia, actuará con dicha calidad durante todo el proceso, dictando acuerdos sobre las pretensiones de los otros dos elementos y realizando las actividades que de oficio sea necesario proveer, las cuales también implican decisión sobre la relación jurídica del proceso. Así, el órgano en mención emitirá autos a fin de hacer comparecer a proceso al inculpado, someterle a prisión preventiva, para que se desahoguen las pruebas

5 Suprema Corte de Justicia de la Nación. 2008. "Ius 2008, Jurisprudencia y tesis aisladas”, [DVD], México D.F., Registros 173,868; 197,432 y 184,164.

6 Levasseur, Georges; Chavanne, Albert; Montreuil, Jean; Bouloc, Bernard; Matsopoulou, Haritini, Droit Pénal Général et Procédure Pénale, Ed. Sirey-Dalloz, París, 1999, pp. 127-129. 
Observación al sentido de los procesos penales mexicanos desde el sistemismo autorreferencial Observation to the meaning of the mexican criminal trials` model by the self-steering systems theory

ofrecidas por los elementos, y continuar de esa manera hasta el dictado del fallo definitivo donde se decide sobre la relación penal motivo del proceso.

Por otro lado, se observó que el Ministerio Público interventor en el proceso realiza funciones exclusivas de acusación, que podrán ser solicitudes de órdenes de aprehensión, ofrecimiento de pruebas para demostrar los elementos del delito y la responsabilidad penal del inculpado, formulación de conclusiones en torno al hecho punible, así como la interposición de recursos en contra de los acuerdos del órgano decisorio, por nombrar algunos.

En lo concerniente al órgano de defensa, se conforma por el inculpado y su defensor, sea particular o de oficio, porque de acuerdo con la observación de las relaciones entre el imputado y el órgano decisorio, el sujeto penal puede defenderse por sí mismo y actuar ofreciendo pruebas, desahogándolas, formulando alegatos, así como ejercer recursos por sí mismo, sin necesidad de solicitud de su defensor. De la misma manera, el defensor particular o de oficio que actúe en el proceso, tiene capacidad para realizar todas las actividades anteriores, sin necesidad de obtener anuencia de su defendido, salvo que éste se oponga de manera expresa a sus actos.

Cabe señalar que los anteriores datos, relacionados con la división de actividades acusatorias, defensivas y decisorias, se obtuvieron de la observación a la redacción de los artículos 20 y 21 de la constitución mexicana, donde se establecen facultades específicas para el Ministerio Público, el órgano de defensa y la autoridad judicial. ${ }^{7}$ Y es ante dicho tipo de relaciones, que se ha determinado la presencia de tres elementos en el sistema procesal penal mexicano: el elemento acusatorio, el de defensa y el decisorio, puesto que las vinculaciones dadas entre aquéllos son substanciales en el sistema, ya que éste no puede operar sin la presencia de dichas relaciones, que presuponen la existencia de los elementos de los cuales provienen las comunicaciones a los demás compuestos.

Ya con la fijación de los elementos sistémicos, fue posible observar que el sistema procesal penal mexicano cuenta con un entorno -el cual rodea a los sistemas sociales y les provee de contenido energético y cognitivo- del cual recibe materia suficiente para operar, como acontece cuando el Ministerio Público investigador envía una consignación ante la autoridad judicial, proveyendo de substancia a un nuevo proceso penal. Dentro del referido entorno se logró la observación de una diversidad de instituciones sociales con las cuales el sistema tiene interacción de manera transitoria, hallándose ahí, desde entes sociales sumamente cercanos, como la físcalía indagadora de hechos penales, hasta algunos alejados que se dedican a la estadística, entre otras actividades, lo cual se constató teniendo en cuenta la división funcional de las distintas instituciones administrativas según la asignación competencial que les proporcionan las leyes constitucionales.

\footnotetext{
Constitución Política de los Estados Unidos Mexicanos, LEX, México D.F., 2009, pp.13-15.
} 
Elías García Rosas

Luis Ávila Benítez

A continuación de esa distinción entre los diferentes organismos sociales que se ubican al exterior del sistema procesal penal mexicano y los elementos de éste, fueron vistos los límites entre el sistema y el entorno. Ellos desde luego no son de carácter físico, más bien, se logran distinguir exclusivamente mediante la observación de los elementos que actúan en el sistema con independencia y autonomía de entidades ajenas, aún cuando éstos permiten ser penetrados actualizando la interdependencia entre sistema y entorno. ${ }^{8}$ Considerando esos lineamientos, fue visto que en particular, los órganos de acusación, de defensa y decisorio, se relacionan cualitativamente en el sistema y así, este último resuelve sus complicaciones, problemas y dilemas mediante recursos propios.

Lo anterior se afirma porque se ha observado que el órgano de acusación acaso generará relaciones conflictivas con los otros dos elementos, a la vez que alguno de éstos también podrá iniciar operaciones intrincadas para los diversos órganos; con todo, el sistema procesal referido, es capaz de solucionar dichos problemas y lograr su estabilidad, o sea, que entre el acusador, el defensor y el decisorio pueden dar fin a cualquier evento surgido con motivo de un proceso penal, sin ayuda de un órgano externo, pues cuentan con sus atribuciones normativas y recursos para ello. ${ }^{9}$ Y si es el caso de que deba tener intervención algún organismo social distinto de los indicados anteriormente, será únicamente con el motivo específico de proveer energía o información al sistema, sin que la institución pueda actuar en ese interior.

Acerca de las operaciones cualitativas en el sistema procesal penal mexicano, se lograron ver por medio de sus estructuras, las cuales se conforman al reconocer aquellas relaciones que se mantienen como una constante y permanecen a pesar de los cambios del ente físico encarnado en el elemento sistémico. ${ }^{10}$ Y como la observación de segundo orden permite apreciar las estructuras latentes en los sistemas ${ }^{11}$ se encontró que esas relaciones estructurales entre los órganos de acusación, de defensa y de decisión judicial siempre prevalecen, con independencia del eventual cambio de titular de la fiscalía, la defensa o el juzgador.

En el sistema procesal penal mexicano también fue visible la existencia de operatividad autorreferente, toda vez que en cada una de sus operaciones se refleja su actuación precedente. Lo anterior indica que una operación sistémica sólo podrá efectuarse a partir de una comunicación provocadora de un proceso al interior del entramado, donde éste atenderá al catálogo de las operaciones que le permiten las estructuras. Y precisamente por las condiciones

8 Corsi, Giancarlo; Esposito, Elena; Baraldi, Claudio, Glosario sobre la Teoría Social de Niklas Luhmann, (traducción de Romero, Miguel y Villalobos, Carlos), Universidad Iberoamericana, México D.F., 2006, pp. 202-203.

9 No se ha presentado el caso, por ejemplo, de que un proceso penal en México quedase suspendido indefinidamente por carencia de recursos sistémicos, de lo contrario se habría documentado ya alguno de esos problemas.

10 García Amado, Juan Antonio. 1989. "Introduction à l'œuvre de Niklas Luhmann”, Droit et Société, No. 11, Francia, pp. 24-26. 
Observación al sentido de los procesos penales mexicanos desde el sistemismo autorreferencial
Observation to the meaning of the mexican criminal trials` model by the self-steering systems theory

estructurales del sistema procesal penal mexicano, éste marcha con estabilidad y su comportamiento es predecible porque se orienta bajo el esquema funcionalmente diferenciado de actividades acusatorias, defensivas y decisorias, derivadas de todas las normatividades de carácter procesal penal, así como las atribuciones constitucionales y orgánicas de los elementos acusador, defensor y decisorio, consolidando así la unidad sistémica.

\section{Observación sistémica al sentido de los procesos penales mexicanos.}

Para abordar este apartado se hace necesario indicar que las estructuras son una herramienta para la reducción de complejidad al interior del sistema, pues según se ha dicho, la complejidad es un estado de carencia informativa para los procesos sistémicos, pero dicha escasez se disminuye mediante la identificación de las estructuras, que establecen una limitación a la inicial libertad de combinaciones entre elementos. Luego, al conocerse la operatividad de un sistema por medio de sus estructuras, se puede efectuar la descripción del funcionamiento sistémico sin necesidad de una determinación exacta de cada momento relacional, es decir, que de una observación inicial es dable determinar el resultado de otras operaciones al saberse cuál es la estructura reguladora de los procesos sistémicos en particular.

Ahora bien, al hacer la selección de operaciones que conforman una estructura al interior de un sistema en aras de reducir la complejidad, se recurre también al concepto de "sentido" en los procesos operativos. Este concepto permite la elección de vinculaciones a partir de una remisión hacia sí, con el fin de conocer qué es lo que pretende consigo mismo y su entorno. ${ }^{12}$ Además, el sentido puede ser considerado como una estrategia determinada para la elección de posibilidades de relación entre elementos en una complejidad; de manera que instituye un límite en la factibilidad de interacción de componentes mediante procedimientos de selección. ${ }^{13}$ Por lo anterior, el sentido se torna un conductor del sistema al erigirse como un medio donde opera la distinción entre actualidad y potencialidad ${ }^{14}$ pues existe una serie de posibilidades relacionales que están presentes y en un momento pueden llegar a actualizarse, caso donde entrará el sentido para filtrar el tipo de relaciones permitidas por las aspiraciones del sistema.

De lo anotado se desprende que la función del sentido en los sistemas sociales es el control al acceso desmedido de posibilidades de relación entre elementos. El sentido permite de esa manera la reducción de complejidad y también hace posible la demarcación de los

11 Molina, Silvia. 2001. "La investigación de segundo orden en ciencias sociales y su potencial predictivo: El caso del proyecto de identidad y tolerancia”, Revista Mexicana de Ciencias Políticas y Sociales, año LXIV, número 182-183, mayo-diciembre, México, p. 23.

Luhmann, Sistemas, cit. nota n. 2, p. 79.

García, Introduction, cit. nota n. 10, pp. 22-23.

Luhmann, Niklas, Introducción a la Teoría de Sistemas, (Torres Navarrete, Javier, Publicador), Universidad Iberoamericana, México D.F., 1996, p. 241. 
Elías García Rosas

Luis Ávila Benítez

límites sistémicos con respecto a su entorno. ${ }^{15}$ Considerando lo precedente, puede decirse que mediante el sentido se obtiene la distinción de límites indicadores de que, en determinado sistema, rigen condiciones específicas de "complejidad reducida"; opuestamente, en el entorno la complejidad es incondicionada e incontrolable.

Ahora bien, Luhmann tiene una visión social-sistémica y por lo tanto concibe al sistema jurídico como parte de la sociedad, que cumple con la función de garantizar las expectativas normativas. ${ }^{16}$ Así las cosas, el sistema de Derecho tendrá los atributos generales de los sistemas sociales: autorreferencia, definición de límites, contacto con el entorno, presencia de estructuras, sentido y actuación de elementos. A lo cual se agregará el código operativo del sistema de Derecho basado en la distinción legal/ilegal y el contenido propio de los sistemas jurídicos: la normatividad. ${ }^{17}$

Las normas, según el concepto de Luhmann, tienen una serie de características muy particulares. Primero, se examinan de acuerdo a las eventualidades de comportamiento frente a ella, considerando las expectativas normativas como contingentes, es decir, con la opción inicial de que se cumplan; pero sin soslayar la factibilidad de que se incumplan, se acaten parcialmente o se desconozcan. Es ante algunas de las conductas anteriores, que el punto de vista sistémico estudia cómo se comportará la norma para lograr su propia estabilidad: quizá sea aplicando la sanción en ella contenida, tal vez recurriendo a otras reglas del entramado jurídico para auxiliar a la estabilización de la expectativa, acaso dejando momentáneamente a salvo las facultades para intentar obtener nuevamente la conducta esperada; o cualquiera otra manera de lograr la expectativa normativa intrínseca. ${ }^{18}$ Con esto se percibe que Luhmann no se basa en un estudio aislado de las normas, sino, al buscar la estabilización de ellas frente a los hechos, reafirma que sólo pueden ser vistas en un contexto sistémico, pues únicamente ahí es donde tiene lugar la estabilización del conjunto normativo y no si se les mira en forma separada.

El segundo tema relevante es que el sistema se orienta por las normas y acepta metas normativas preestablecidas, concediéndose así a aquéllas otro papel de suma importancia: como orientadoras del sentido del sistema. Esto implica que se constituyen en directrices para la operatividad sistémica y las estructuras, concordadas con el sentido normativo. ${ }^{19}$

\footnotetext{
15 Por eso se dice en el campo del sistemismo, que las fronteras de los entramados sociales no son físicos, sino de sentido porque se sustentan en la señalización de las posibilidades de vinculación elemental, pero no en limitantes materiales ni espaciales.

16 Luhmann, Niklas, Sistema Jurídico y Dogmática Jurídica, Centro de Estudios Constitucionales, Madrid, 1983, p 27.

Corsi, Giancarlo; Esposito, Elena; Baraldi, Claudio, Glosario, cit. nota n. 8, pp. 71-73.

Luhmann, Niklas, El Derecho de la Sociedad, Universidad Iberoamericana, México, 2002, pp. 181-221.

Luhmann, El Derecho, cit. nota n. 18, pp. 141, 276, 308, 309.
} 
Observación al sentido de los procesos penales mexicanos desde el sistemismo autorreferencial Observation to the meaning of the mexican criminal trials` model by the self-steering systems theory

La tercera distintiva del sistema de Derecho, es que opera por medio de normas "válidas"; pero Luhmann estima válidas las normas positivas en tanto cuenten con capacidad para lograr una comunicación dentro del sistema jurídico, dejando a un lado la calificación de aquéllas basada en un contenido valorativo, pues éste ya se halla inscrito en los "programas". Los programas son aquellas reglas que fijan las condiciones para que una determinada operación pueda considerarse adecuada con el código del sistema. En el sistema del Derecho los programas son aquellas reglas donde se establecen, además de los contenidos normativos específicos del sistema particular, la asignación de los valores: las leyes. En el ámbito de la investigación, tanto los códigos como los programas pueden ser apreciados y descritos por un observador secundario como la estructura del sistema. ${ }^{20}$

La última característica de la óptica normativa de Luhmann, que deriva mediatamente de su concepto en torno a la validez jurídica, es que el orden normativo no está determinado de manera jerárquica, sino heterárquica, esto es, colateralmente y estructurado en forma de redes, donde se otorga mayor valor a la aplicación normativa que a la jerarquía de ciertas disposiciones. ${ }^{21}$

Fue el segundo de los caracteres citados el de mayor importancia para la presente investigación, porque en él se centra la cuestión de los indicadores normativos como orientadores de un entramado de Derecho. Entonces, lo que un sistema jurídico "pretende consigo mismo" (sentido) está precisamente señalado por la normatividad legal conformadora del programa sistémico, por lo tanto, el punto de correlación del sentido en la materia procesal penal es lo que se conoce como fin o fines del proceso.

Acerca de este punto, no basta que los ordenamientos reguladores del proceso penal inserten en su articulado el propósito específico de su operatividad -como algunos lo hacen-, sino que éste se establece mediante la observación a su contenido normativo integral y sobre todo su operatividad, considerando que dicho contenido se constituye en un indicador de su sentido. No se busca aquí, empero, hallar los fundamentos genéricos de creación de los procesos penales, porque se redundaría en el fin general del Derecho acorde al sistemismo: garantizar esperanzas normativas. Más bien, se acude al entramado procesal para distinguir cuáles son esas expectativas en el objeto de estudio particular, en nuestro caso: a dónde conduce toda la serie de disposiciones legales moderadoras de los procesos penales mexicanos en el funcionamiento sistémico.

Se halló sobre este particular una diversidad de opiniones en torno al fin del proceso penal, mismas que fueron usadas en la presente investigación como equivalentes funcionales para incrementar la fiabilidad del estudio, puesto que según la teoría sistémica seguida, la 
Elías García Rosas

Luis Ávila Benítez

correcta explicación a los fenómenos a partir del método funcional, se constituye mediante la "expansión (en general) y la limitación (en concreto) de las equivalencias funcionales". ${ }^{22}$

Atendiendo a la frase referida en el párrafo precedente, ${ }^{23}$ las posturas de los doctrinarios sobre el fin del proceso penal mexicano se tuvieron como paridades funcionales para el análisis en cuestión y se encontró que inicialmente los dividen en fines inmediatos y mediatos. Los inmediatos, o generales, los hacen consistir en la aplicación de la ley al caso concreto y la sujeción de esa aplicación legal a determinadas reglas. Consideran los doctrinarios, por otra parte, los fines mediatos o específicos del proceso, que se fijan con el hallazgo de la verdad histórica, la obtención de la personalidad del delincuente y el mantenimiento de la paz social. ${ }^{24}$ Por otra parte, revisados que fueron los códigos de procedimientos penales mexicanos, se detectó que en su mayoría no indican sus propósitos de acción, y en los ordenamientos que sí se hace, se encuentra el hallazgo de la verdad histórica como motivo fundamental del proceso (Chihuahua, artículo 1); la verdad procesal (Oaxaca, artículo 1); o la "declaración de existencia del delito y en su caso la condena con sus consecuencias" (Coahuila, artículo 2; Jalisco, artículo 3; Tabasco, artículo 1; Veracruz, artículo 2): ${ }^{25}$ en cuanto a la Carta Magna mexicana no contiene directriz alguna sobre ese punto ${ }^{26}$ ante lo cual se acudió a la interpretación jurisprudencial de esos contenidos normativos para visualizar con qué intención le aprecian los intérpretes judiciales.

Se encontró así que los creadores de la jurisprudencia legalmente autorizada consideran a la aplicación de la ley por una autoridad judicial como una finalidad del proceso. ${ }^{27}$ Asimismo estiman como fin procesal el hallazgo de la verdad histórica, según el vasto número de tesis que han emitido en ese sentido. ${ }^{28}$ También tienen en cuenta encontrar la

Luhmann, Sistemas, cit. nota n. 2, p. 72.

La cual puede traducirse en que acorde al método funcional, los potenciales explicativo y de seguridad del método indicado aumentan al reducirse fundadamente las opiniones de solución en torno al problema mediante el ejercicio comparativo de las equivalencias.

Barragán Salvatierra, Carlos, Derecho Procesal Penal, Editorial Mac Graw Hill, México D.F., 1999, pp. 80-82; Colín Sánchez, Guillermo, Derecho Mexicano de Procedimientos Penales, Porrúa, México D.F., 1999, pp. 8184; Díaz de León, Marco Antonio, Diccionario de Derecho Procesal Penal, Porrúa, México D.F., 1997 p. 1770 ; Rivera Silva, Manuel, El Procedimiento Penal, Porrúa, México D.F, 1993, p. 25.

Orden Jurídico Nacional. 2009. "Códigos de Procedimientos Penales para los Estados integrantes de la República Mexicana; de procedimientos penales federales; y, para el Distrito Federal", México, disponible en http:// www.ordenjuridico.gob.mx/. [Visitado el 18.01.2009].

Constitución, cit. nota n. 7. No se soslaya la existencia de reformas a la Carta Magna mexicana de fecha 18 de junio del año 2008, consultables en este mismo texto, las cuales tienen una vacatio legis de ocho años. En ellas se indica en el artículo 20, apartado “A”, Fracción I, que el propósito de los procesos penales es el "esclarecimiento de los hechos".

Suprema Corte de Justicia de la Nación, Ius 2008, cit. nota n. 5, registros 175,807; 304,025; 186,613 y 233,092. Suprema Corte de Justicia de la Nación, Ius 2008, cit. nota n. 5, registros 171,080; 175,481; 175, 929; 178,933; 180,$187 ; 183,054 ; 189,763 ; 197,998 ; 198,947 ; 200,974 ; 201,200$ y $216,066$. 
Observación al sentido de los procesos penales mexicanos desde el sistemismo autorreferencial
Observation to the meaning of the mexican criminal trials` model by the self-steering systems theory

personalidad del delincuente a título de fin procesal, como es desprendido de las tesis respectivas. ${ }^{29}$

En este sentido, luego de la detección de distinciones en torno a los fines del proceso penal hechas por los doctrinarios, los ordenamientos procesales penales mexicanos y los intérpretes judiciales también de esta nacionalidad, se consideró cada una de ellas como equivalente funcional para observarles en el desempeño sistémico y constatar cuál de ellas funciona a manera de rectora eficiente en plena congruencia con todo el entramado.

Con antelación a ello, fue necesario determinar el desarrollo sistémico procesal penal, esto es, el inicio y culminación de la fase procesal propiamente dicha, haciéndose necesario en acatamiento al método sugerido por el sistemismo- partir de las estructuras procesales penales mexicanas, dadas por la división funcional de los entes acusador, defensivo y decisorio en la red de mérito, y primordialmente, atendiendo al contenido normativo procesal como un orientador del sentido del sistema.

Fue hallado así que los códigos de procedimientos penales mexicanos ${ }^{30}$ establecen la necesidad de intervención judicial para iniciar la fase de proceso; y que esta etapa puede concluir de maneras diversas, bien mediante sentencia definitiva o a través de las múltiples figuras extintoras de la acción penal que a la postre provocan el sobreseimiento, que es una manera anormal de terminación del juicio pero que le decide en definitiva y le da efectos de cosa juzgada. $^{31}$

De ahí se logró observar que el proceso penal inicia desde el momento en que se ejercita la acción penal en contra de persona determinada y es mediante esa energización al complejo de mérito que se provocan diversos acontecimientos al interior, pues la consignación ministerial ante el órgano judicial provocará que éste se avoque al conocimiento de los hechos y provea su primer acuerdo decisorio resolviendo sobre la petición de acusación inicial. Según las legislaciones procesales antes citadas, también se dará oportunidad al órgano defensor para que realice todas las actividades conducentes a contradecir el acervo probatorio aportado por el ente acusador; y en estos casos, el decisorio igualmente habrá de proveer acerca de las solicitudes de defensa.

De tal manera que el proceso penal se desarrollará al tenor de las operaciones efectuadas en su interior por los órganos acusador, defensor y decisorio, mediante fases sucesivas y de manera organizada estructuralmente. En este sentido y a diferencia de otro tipo de sistemas 
Elías García Rosas

Luis Ávila Benítez

sociales, en el procesal penal mexicano puede visualizarse una etapa final de cada una de las operaciones recursivas, puesto que su operatividad (sólo en lo concerniente al asunto procesal específicamente observado) cesa al momento en que se obtiene la decisión final e inatacable de la autoridad judicial.

Así se percibe del programa conformado por los ordenamientos procesales penales nacionales donde se establecen (en todos ellos) distinciones entre las etapas que han de proseguir ininterrumpidamente y las que dan término a la operatividad, ${ }^{32}$ notándose que hay una diferencia fundamental en las actuaciones con continuidad y aquéllas que finalizan el proceso particular, pues las primeras hacen que los períodos se sucedan unos a otros sin que pueda dejarse alguno inconcluso, encontramos ahí las operaciones mediante las cuales se resuelve la detención de una persona, la realización de la declaración preparatoria, la emisión del auto de procesamiento, la apertura de juicio a prueba, la recepción de probanzas, el desahogo de órganos de prueba, el cierre de instrucción, la escucha de conclusiones, entre otras; mientras que las segundas impiden definitivamente que se reestablezca la continuidad sistémica pues se carece de finalidad para ello por haberse ya agotado el presupuesto de existencia procesal, se trata aquí de los asuntos resueltos mediante sentencia definitiva y por cualquier otro supuesto que atraiga conclusión anormal del juicio mediante sobreseimiento como el perdón del ofendido, prescripción de la acción penal, abrogación de la ley, y preclusión de derechos procesales inherentes al ejercicio de la acción penal, por ejemplo.

Lo anterior se develó mediante la observación al programa procesal penal mexicano, donde fue visto que si se surten las hipótesis de sobreseimiento - por cualquier razón- o de sentencia definitiva en el juicio, ${ }^{33}$ ya no habrá ulteriores etapas de realización procesal. Sistémicamente nada queda ya a los órganos por hacer en estos casos, salvo trámites de índole simplemente administrativa, como devolución de cauciones otorgadas o aplicación de éstas a los fondos del Estado, pero de ninguna manera en torno al fondo del asunto, por haberse éste solucionado firmemente. Puede determinarse que en estos casos, resuelta la causa penal mediante sobreseimiento o sentencia, la actividad acusadora de la fiscalía habrá finalizado y asimismo lo estará el trabajo defensor y desde luego la función judicial del ente decisorio. Esto provoca que al quedar firme una de las resoluciones con las características antes indicadas, cesará la continuidad sistémica del proceso penal y no habrá manera de reiniciarle porque se estaría juzgado doblemente sobre los mismos hechos. Por tanto, esas determinaciones finales del proceso funcionan en el caso para tenerles como un equivalente funcional con la suficiente idoneidad para desplazar a los otros aludidos en párrafos anteriores y que permiten llevar a la conclusión de que el sentido de los procesos penales mexicanos, visto desde el sistemismo

\footnotetext{
32 Orden Jurídico Nacional, Códigos, cit. nota n. 25.

33 Se está hablando aquí de ejemplos donde la resolución haya causado ejecutoria, porque de lo contrario sus efectos no se producen, ante la eventual interposición de algún medio de impugnación.
} 
Observación al sentido de los procesos penales mexicanos desde el sistemismo autorreferencial Observation to the meaning of the mexican criminal trials` model by the self-steering systems theory

autorreferencial de Niklas Luhmann, es la decisión judicial definitiva, pues obtenida ésta en una particular causa (expediente judicial), cesa la sucesión operativa de la indicada red jurídica.

Y es aquí donde se notan las ventajas del empleo de la corriente sistémica autorreferente, pues para sostener el anterior indicador, se efectuó la reducción de posibilidades contrastándole con los fines sostenidos por los doctrinarios, los plasmados en los códigos procesales penales mexicanos y los reconocidos en la interpretación jurisprudencial que ya han sido señalados.

Se halló así, que en lo referente al más lato de ellos, consistente en la aplicación de la ley al caso concreto, presenta vaguedad en cuanto a la "ley que debe aplicarse" al asunto específico, puesto que la subsunción legal puede realizarse por el organismo decisorio en todo momento, más aún si se trata de disposiciones procesales, pues es menester emplear alguna o varias de ellas para emitir hasta el proveído más simple por una autoridad. Y no se puede mirar diferente este tema de la aplicación de la ley, porque si se quisiera entender alusión a la aplicación de las disposiciones penales sustantivas, la conformación elemental sería diversa a la actual, a fin de dejar en manos del ente judicial la facultad para controlar las pruebas así como la duración del proceso hasta lograr la actualización de la sanción a persona alguna, con lo cual tendríamos procesos con temporalidad prácticamente indefinida para los casos donde hubiera problema de identidad del realizador conductual, hasta que se recabaran las pruebas suficientes para condenar al sujeto a proceso.

En cuanto al tópico que señala como fin del proceso a la "sujeción de esa aplicación legal a determinadas reglas", debe considerarse el mismo vicio de origen que para el anterior tema, esto es, ab initio se desconoce cuál es la ley específica de aplicación potencial; además que los pasos ordenados aludidos, no son realmente el sentido del proceso, sino el medio para actualizarle y están dados por la conformación estructural procesal, ante lo cual, de considerárseles como sentido del proceso, se estaría confundiendo su finalidad con la reglamentación para conseguirle.

El sentido del proceso penal mexicano tampoco lo es el hallazgo de la verdad histórica, debido a que según se ha apuntado, los sistemas jurídicos se encuentran diferenciados funcionalmente por el código legal/ilegal, en tanto que la materia de la historicidad tiene sus propios valores de distinción y se rige por el código histórico/ahistórico. De esta manera se tiene que el proceso penal habrá de seguir su desarrollo con apego a una serie de reglamentaciones preestablecidas -todas de índole jurídica- y el sistema sólo debe operar si las comunicaciones al interior cumplen con las características de legalidad. En cambio, el sistema histórico opera sin diferenciar si el acontecimiento tiene matices de legitimidad o es totalmente ilegal, ya que se limita a indagar los sucesos y registrarles como antecedente. Esta tangible diferencia entre los códigos diferenciadores de las funciones de un sistema jurídico y otro histórico permiten claramente determinar que el fin del proceso penal mexicano no puede estar dado por la búsqueda de la verdad histórica, pues ésta pertenece a una materia ajena y con códigos funcionales propios. 
Elías García Rosas

Luis Ávila Benítez

Llevado el anterior postulado a la práctica procesal, obligó a plantear que los procesos penales no tienen el sentido de hallar la verdad histórica, pues el órgano decisorio tiene los recursos para resolver definitivamente un asunto penal con el mínimo de pruebas en una causa legalmente no existen condicionantes a ese respecto-y por tanto los procesos pueden finalizar aún sin prueba alguna, es decir, a pesar que la verdad histórica permanezca totalmente desconocida y no se logre su fijación en el curso procesal. Pensar contrariamente también llevaría a sostener que los procesos concluirían hasta el momento en que se lograra desentrañar la verdad histórica de los hechos motivo de juicio, ante lo cual sería necesario replantear todo el esquema operativo procesal para dar inclusión al código histórico y desde luego habría de disminuirse a los justiciables sus garantías constitucionales para ser juzgados en plazos establecidos por la Carta Magna a fin de asegurarse de fallar un caso penal hasta que se logre establecer la verdad histórica; aspectos que son inaceptables desde la óptica sistémica autorreferente.

Con estos mismos fundamentos se pudo dejar a un lado el equivalente funcional de fijar la personalidad del delincuente como el sentido del desarrollo procesal penal mexicano, pues en tal caso, los juicios estarían dirigidos específicamente a recabar pruebas para conocer las características personales de los justiciables y, recibidas éstas podría finalizarse el proceso sin mayor problema. Lo precedente tampoco es aceptable conforme a la corriente social aquí seguida, en atención a que el hallazgo de las cuestiones relacionadas con la personalidad de los inculpados es problema principal de diverso campo, y en el procesal penal sólo se torna como un orientador respecto de la posible punición que se llegase a imponer al responsable de un asunto específico terminado mediante condena. Pero considerando que no todos los procesos concluyen con sentencias condenatorias, sino que también se presentan absoluciones e inclusive que algunos no llegan hasta esa etapa, el tema de mérito carecería de actualización como un indicador del sentido sistémico, debido a que se dejarían fuera todos los otros asuntos donde no tuviere injerencia la personalidad del delincuente. ${ }^{34}$

El sustento de la paz social igualmente quedó fuera como indicador del sentido del sistema procesal penal mexicano, pues el programa inserto en las normas correspondientes no contempla una interacción fundamental con los organismos que pudiesen informarle el momento en que se altere esa paz social. Además, este supuesto puede ocurrir por diversas razones, dado que la estabilidad en los comportamientos sociales se rompe por múltiples fenómenos relacionados con conductas de particulares, pero también de las autoridades, de tal suerte que pudiese ser incluso una decisión judicial la que venga a causar disturbio al sentir social, como el ejemplo donde una decisión de libertad a cierta persona provoque descontento a los miembros de la

34 Tales como las resoluciones donde se decreta la prescripción de la acción penal, procedencia de perdón del ofendido, preclusión de oportunidad para promover eficientemente por la fiscalía ante autos de libertad transitoria, entre otros. 
Observación al sentido de los procesos penales mexicanos desde el sistemismo autorreferencial Observation to the meaning of the mexican criminal trials` model by the self-steering systems theory

sociedad y rompa con esa tranquilidad regular. Entonces, pudo establecerse que la conclusión de los procesos no solo es ajena al mantenimiento de la paz social, sino que en algunos casos es lo que viene a quebrantarla, lo cual permitió descartar este equivalente funcional como sugestivo del sentido del sistema estudiado.

De las argumentaciones dadas en estos párrafos también se deriva que el sentido de los procesos penales mexicanos tampoco lo es la fijación de la verdad procesal, pues el contenido de las resoluciones solo es un pronunciamiento de procedencia de una acción penal y de ciertas pretensiones accesorias a ella; pero cuando el proceso concluye de manera anticipada (por una figura que no es sentencia) queda trunca esa finalidad y por ende no puede considerarse sistémicamente como la rectora procesal por excelencia. Este argumento también excluye al diverso motivo consistente en "la declaración de existencia del delito y en su caso la condena con sus consecuencias", que se inserta en algunos códigos adjetivos penales porque tampoco se actualizaría en soluciones procesales penales anticipadas a la sentencia, como se ha explicado previamente.

\section{Conclusiones}

1. La teoría de sistemas autorreferenciales, si bien, de poco uso para temas específicos implicados con el Derecho, resulta con aplicación para el estudio de objetos jurídicos; para ello habrán de tenerse en cuenta los componentes generales de esa corriente con respecto a la conformación de los sistemas, a saber: entorno, elementos, límites, estructuras, autorreferencia y sentido; además, será de considerarse el tema de la normatividad, propio de los entramados jurídicos, donde se torna un indicador del sentido sistémico y se materializa mediante programas conformados en las leyes.

A partir de lo anterior, es dable determinar que una manera aceptable para realizar una observación a cierto sistema jurídico, es iniciar situando correctamente el entorno en que se encuentra y su manera de interacción como proveedor energético y cognitivo. Con el propósito de lograr tal fijación pueden distinguirse las unidades irreductibles de operación, para que de esa diferencia y la conformación estructural directora del entramado, se conozcan las fronteras sistémicas, e igualmente se aprecie la operatividad de la red jurídica con base en su propia actuación precedente y su sentido. Todo esto sin soslayar que tanto la conformación estructural como el sentido, están constituidos por el programa inserto en las leyes válidas para el sistema.

Considerando estos conceptos, tenemos que el proceso penal mexicano, visto desde la corriente sistémica autorreferente, puede ser fijado con la observación de los límites que le diferencian del entorno que le rodea, donde hay variedad de organismos sociales en su mayoría de carácter administrativo. Dicho entramado es apreciable a través de la precisión de sus elementos, que son los órganos de acusación, defensa y decisión; quienes operan 
Elías García Rosas

Luis Ávila Benítez

en su interior a través de comunicaciones reguladas por sus estructuras, dadas en razón del contenido normativo. De igual manera, debe considerarse su capacidad operativa a través de la autorreferencia y su conformación estructural para el funcionamiento sustentado en la división de actividades de los elementos acusatorio y defensivo, escisión que se constituye en programa y deriva de las normas Constitucionales y procesales de los códigos nacionales.

2. El sentido en los sistemas sociales es una estrategia de selección para delimitar las posibilidades de relación entre elementos dentro de la complejidad en que se encuentran; se constituye como un límite en la interacción de componentes mediante procedimientos de selección, tornándose así en un conductor del sistema. En el caso de los sistemas de Derecho, su sentido se halla orientado por las normas, que a su vez conforman el programa sistémico y se hallan en las leyes válidas al interior sistémico.

Bajo este esquema, se pudo determinar que para descubrir el sentido de determinado sistema jurídico, es necesario observar su programa mediante la apreciación de las leyes válidas para el entramado contenidas en las diversas codificaciones aplicables; y de ahí reducir los equivalentes funcionales hasta llegar a desentrañar la verdadera intención sistémica, teniendo en cuenta aquí, como indicadores confiables acerca del funcionamiento operativo, los momentos en que inicia la acción particular del sistema y dónde termina su operatividad, porque ahí es donde se refleja en mayor grado su sentido, siendo aquí donde resalta la ventaja de utilizar la corriente sistémica autorreferencial, porque permite efectuar comparaciones ordenadas y alcanzar resultados fiables.

3. Tratándose del sistema procesal penal mexicano, fue encontrado que su desarrollo, en cuanto a un asunto específico, inicia con la energización que provee el Ministerio Público investigador al ente decisorio al momento de ejercitar acción penal, con lo cual nace el proceso y comienzan sus fases que se verifican mediante comunicaciones hechas entre los órganos de acusación, defensa y decisión, continuándose hasta llegar a la conclusión total del asunto especialmente observado, que puede ser mediante sentencias definitivas o cualquiera otra manera de dar solución final al caso por el ente decisorio, quien goza de esa atribución para culminarle; en este momento el acusador y el decisorio ya no tendrán mayores actividades por realizar en el entramado procesal penal. De ahí se llegó a la conclusión de que el sentido de dicho sistema es la decisión judicial definitiva, pues con ella se da término a la cognición recibida del entorno y se concluyen las labores de las entidades sistémicas irreductibles que son el Ministerio Público, la institución defensora y el órgano judicial conocedor del caso.

Hay otros temas que doctrinaria y jurisprudencialmente son tenidos a título de fines del sistema procesal penal mexicano, como la aplicación de la ley al caso concreto, el 
Observación al sentido de los procesos penales mexicanos desde el sistemismo autorreferencial Observation to the meaning of the mexican criminal trials` model by the self-steering systems theory

seguimiento de determinadas reglas para esa aplicación, el hallazgo de la verdad histórica o procesal, la obtención de la personalidad del sujeto a proceso, el mantenimiento de la paz social, y, las declaraciones de existencia del delito con sus consecuencias correspondientes. Pero estos rubros no pueden considerarse como conformadores del sentido de los procesos penales, pues mediante las ventajas que proporciona el sistemismo luhmanniano, como la reducción funcional, se determinó que aún cuando alguno de aquellos aspectos se hubiese conseguido, no se llegaría a la culminación procesal, o bien, ésta se produce en otros casos con independencia de que no se hubiese actualizado alguno de los equivalentes funcionales distintos a la decisión judicial definitiva. Luego, únicamente han servido en el estudio para comprobar la seguridad del dato correspondiente a que el verdadero sentido del sistema es la decisión judicial definitiva, pero no pueden considerarse como el sentido del entramado que fue motivo de análisis. 